\title{
Writing to Learn Engineering: Identifying Effective Techniques for the Inte- gration of Written Communication into Engineering Classes and Curricula (NSF RIGEE project)
}

\section{Dr. Cary David Troy, Purdue University, West Lafayette}

Ph.D., Stanford University, School of Civil and Environmental Engineering (2003) Assistant Professor, Purdue University, School of Civil Engineering (2007-present)

\section{Ms. Rebecca Rose Essig, Purdue University}

Prof. Brent K Jesiek, Purdue University, West Lafayette

Dr. Brent K. Jesiek is Assistant Professor in the Schools of Engineering Education and Electrical and Computer Engineering at Purdue University. He is also an Associate Director of Purdue's Global Engineering Program, leads the Global Engineering Education Collaboratory (GEEC) research group, and is the recent recipient of an NSF CAREER award to study boundary-spanning roles and competencies among early career engineers. He holds a B.S. in Electrical Engineering from Michigan Tech and M.S. and Ph.D. degrees in Science and Technology Studies (STS) from Virginia Tech. Dr. Jesiek draws on expertise from engineering, computing, and the social sciences to advance understanding of geographic, disciplinary, and historical variations in engineering education and professional practice.

\section{Prof. Josh Boyd, Purdue University}

Josh Boyd is associate professor and director of undergraduate studies in the Brian Lamb School of Communication.

\section{Natascha Michele Trellinger, Purdue University, West Lafayette}

Natascha Trellinger is a first year PhD student in the School of Engineering Education at Purdue University. She received her BS in aerospace engineering from Syracuse University. At Purdue, Natascha is a part of the Global Engineering Education Collaboratory (GEEC) and is interested in global teaching and learning at both the undergraduate and graduate levels. 


\section{Writing to Learn Engineering:}

Identifying Effective Techniques for the Integration of Written Communication into Engineering Classes and Curricula 


\begin{abstract}
As engineering continues to grow as a global career, effective communication in the form of technical writing becomes more essential. Professional engineering organizations and universities continually list the ability to communicate technical information as a highly sought attribute in recently-graduated engineers. Unfortunately, numerous logistical challenges prevent many programs from implementing extensive technical writing education within the engineering curriculum. These challenges include budgetary constraints, curriculum credit hour reductions, availability of communication expertise, and both student and faculty resistance to the inclusion of communication instruction in engineering programs. This study aims to identify and refine effective, low-overhead exercises that allow instructors to implement technical writing education into technical existing technical courses. These exercises have the benefit of embedding technical communication into the curriculum, with minimal curricular disruption, and in the context of the technical material that will ultimately need to be communicated. The project proposes innovative application of writing interventions that have been proven effective in other contexts, with the goal of transforming core technical courses in engineering to enhance both the technical capabilities and writing skills of participating students. Initial analysis focuses on the implementation of two technical writing interventions developed and applied to Civil Engineering courses. Preliminary study results on a large course paragraph writing exercise point to the importance of the development of a robust assessment and feedback strategy for the implementation of writing in large classes, as well as the different types of writing that can successfully be incorporated into such classes, in spite of their technical nature.
\end{abstract}

\title{
Introduction
}

Communication skills are immensely valuable for today's engineering graduates (Riemer, 2007). Modern engineers are expected to not only produce technically appropriate designs, but to communicate these designs in written, oral, and graphical form to a variety of audiences ranging from their technical peers to the general public. Indeed, almost all professional engineering organizations cite effective communication skills as a top priority for graduating engineers. For instance, the National Academy of Engineering (NAE)'s The Engineer of 2020: Visions of Engineering in the New Century outlines expectations for engineers entering practice within the near future (National Academy of Engineering, 2004). The report states that it is impossible to practice engineering without communication, and engineers functioning in global networks must have "an ability to communicate convincingly and to shape the opinions and attitudes of other engineers and the public." Moreover, communication in engineering is not merely the "icing on the cake", but rather frequently constitutes part of the cake itself. Numerous engineering failures have occurred as a result of poor communication, including the Space Shuttle Challenger disaster (1986) and the oft-cited loss of the \$125M NASA Mars Climate Orbiter (1999), which resulted from a failure to communicate the units required for the navigation software.

Accordingly, ABET has required communication skill development within the engineering curriculum for almost two decades (Riemer, 2007). Specifically, ABET's EC2000 accreditation framework lists "an ability to communicate effectively" as a key learning outcome (ABET, 
2012). Another recently published list of attributes important for global engineers similarly lists: "Communicates effectively in a variety of different ways, methods, and media (written, verbal/oral, graphic, listening, electronically, etc.)" and "Communicates effectively to both technical and non-technical audiences" (International Federation of Engineering Education Societies, 2013).

What these and many other leading institutions have recognized is that writing is a particularly essential element of all engineering communication. Engineers write to transmit information in all stages of their projects and design development. In fact, a study published in 2011 found that practicing engineers at four different US firms and two Indian firms spent over half of their day communicating through email and other messaging (Levine, Allard, \& Tenopir, 2011). Formally, these writings are in the format of proposals, memos, emails, progress reports, fabrication instructions, and final reports. These documents require skills and knowledge in a wide range of writing components, including structure and organization, document formatting, graphics, and audience and genre awareness (Plumb \& Scott, 2002).

In addition transmitting engineering knowledge, writing is essential to generation of knowledge (Winsor, 1990), and is also an essential partner to the engineering process itself (Levine, Allard, \& Tenopir, 2011). Many scholars recognize that writing is engineering, and that it is very difficult, if not impossible, to engineer without writing (Winsor, 1990). And while the importance of writing in engineering is often vastly underappreciated by engineers, a simple examination of where informal writing occurs in engineering reveals that it is omnipresent in the form of handwritten notes, sketches, informal emails, journals, logs, recorded data, and equipment manuals (Winsor, 1990). Writing also plays a critical role in the design process (Dym, Agogino, Eris, Frey, \& Leifer, 2005), and the design process and the writing process have many parallels, with some suggesting that they are in many ways similar or even identical. Indeed, it is easy to see how the craft of writing - from scattered first words and ideas, through draft, review, and revision, to final submitted product (and back through draft, review, and revision) - bears immense similarity to the engineering design process.

\section{Why Engineers Should Write to Learn: Importance of Writing in an Engineer's Education}

One leading argument for the importance of writing in engineering education centers on enhanced learning outcomes. The writing-across-the-curriculum movement is based on the notion that students from all disciplines need practice writing (Russell, 1992), in part because writing and the ability to think critically seem to be linked (Bean, 1996). Students improve their thinking and knowledge acquisition through writing (Bazerman, Little, Bethel, Chavkin, Fouquette, \& Garufis, 2005), a process often called "writing-to-learn" (Olds, Dyrud, Held, \& Sharp, 1993). Pioneering research by Light (Light, 2004) has also shown that the amount of writing in a course is more strongly linked to increased student engagement than any other course characteristic. So apart from the obvious practical importance that engineers should be able to write well, there is also substantial learning that takes place through the process of thinking and planning that is required for good writing. The learning associated with writing is similar to the learning associated with teaching, as both involve the organized communication of information to an external audience. 
Writing also plays an important role in many proven engineering pedagogical techniques, including cooperative learning, active learning, and problem-based learning (PBL) strategies (Wheeler \& McDonald, 2000). Active learning techniques are especially effective, and writing is an important ingredient in many active learning exercises (Felder, Woods, Stice, \& Rugarcia, 2000). Writing exercises and activities are frequently suggested as a relatively low-barrier approach to promoting active learning, including in lecture courses (Bean, 1996). Writing is also particularly important for students with certain learning styles (Felder, Learning and Teaching Styles in Engineering Education, 1988).

Further, the inclusion of writing in an engineering curriculum may be especially salient for underrepresented groups in engineering. Written communication has been shown to provide a lower stress outlet for students to organize and develop concepts learned within a course (Hawkins, Coney, \& Bystrom, 1996). And for linguistic minorities who speak a vernacular variety of English that differs in many respects from the written standard for (engineering) communication, the inclusion of writing instruction may be even more essential (Whiteman Farr, 1981), albeit not straightforward (Jenkins, Jordan, \& Weiland, 1993).

\section{Incorporation of Writing in University Engineering Programs}

While a strong case can be made for the importance and value-add of writing in engineering, there remain many questions about how to best incorporate writing into engineering degree programs. In this section we review a number of strategies, beginning at the curriculum level and then delving into the course level, including a review of two main types of writing assignments.

Curriculum-Level Approaches to Writing in Engineering At the curriculum level, many organizational structures exist for the incorporation of technical writing into an engineering curriculum (Held, et al., 1994; Ford \& Riley, 2003). Given the resources required for these programs and writing centers (Walker, 2000), these programs are generally targeting (ABETrequired) technical writing proficiency in students, as opposed to the inclusion of writing to enhance learning of technical material. Curriculum-level approaches to teaching engineering writing can generally be categorized relative to two extremes along the integration spectrum, namely: (a) a highly focused delivery of writing instruction, with the most focused delivery being a single, stand-alone course in technical communication, or (b) a diffused approach, in which technical writing instruction is integrated throughout the curriculum.

\begin{tabular}{|c|c|c|c|c|}
\hline Case & Year 1 & Year 2 & Year 3 & Year 4 \\
\hline a & $\begin{array}{c}\text { Formal writing in } \\
\text { composition and } \\
\text { communication course }\end{array}$ & None & None & $\begin{array}{c}\text { Formal writing in } \\
\text { Senior Design or } \\
\text { Capstone course }\end{array}$ \\
\hline \multirow{2}{*}{ b } & $\begin{array}{c}\text { Case (a) plus } \\
\text { incidental writing in } \\
\text { first-year courses }\end{array}$ & $\begin{array}{c}\text { Incidental writing in } \\
\text { core classes }\end{array}$ & $\begin{array}{c}\text { Incidental writing in } \\
\text { core classes and } \\
\text { technical electives }\end{array}$ & $\begin{array}{c}\text { Case (a) plus } \\
\text { incidental writing in } \\
\text { technical electives }\end{array}$ \\
\cline { 2 - 5 }
\end{tabular}

Figure 1: Writing expectations for typical (a) focused delivery and (b) diffused approaches 
While case (a) remains prevalent in many engineering programs, case (b) is likely a much more effective strategy since it involves both focused writing instruction as well as integrated writing in the discipline (WID) (Petraglia, 1995). In fact, there are many arguments for including writing across the engineering curriculum, and throughout an engineer's education. First, it is proposed that technical writing is best learned in the context of the technical material being communicated (Buzzi, Grimes, \& Rolls, 2012). When writing is only addressed in a communications course, it perpetuates the myth that writing is not an important part of actual engineering. The inclusion of writing in technical courses stresses the importance of writing to developing engineers and encourages them to develop the necessary proficiency desired by employers. Second, proficiency in technical writing is developed slowly, through consistent practice and effort over a student's four-year degree, not over a single semester. When writing is included in "regular" engineering courses, the learning of the technical content in those courses is greatly enhanced (writing is active; writing encourages critical thinking). Third and finally, writing is one of the only ways to address professional and global skill development, e.g.: the broad education necessary to understand the impact of engineering solutions in a global, economic, environmental, and societal context; a recognition of the need for, and an ability to engage in life-long learning; and knowledge of contemporary issues (ABET, 2012).

Course-Level Approaches to Writing in Engineering The idea of writing-across-thecurriculum assumes that writing will be part of disciplinary instruction. In other words, when students have to write a lab report, they will be accountable not only for results, but also for the way those results are presented. If students have to answer an applied problem, they need to be able to record not only a number, but also put that number in context through clear and effective writing.

Yet how might instructors best incorporate technical writing instruction in their courses? To bring about this seemingly simple synthesis of writing and disciplinary learning, several pedagogical elements are needed. First, instructors should help students learn the conventions of their technical discipline. What are appropriate forms of notation? What are the requirements for documentation? What are expectations of length, or level of detail? This can be modeled, of course, and students will learn some by reading examples of disciplinary writing, but these basic conventions do not "go without saying." They provide a framework within which students work.

Second, the criteria for evaluating writing must be clear. This involves very specific assignment parameters as well as clear and consistent rubrics that outline evaluation criteria. These rubrics can be analytic (e.g., with points awarded in several categories leading to a total score) or holistic (with one overall writing score awarded based on norms of each score provided to students). They can separate writing from disciplinary content, or they can integrate the two in the evaluation process. One of the most critical and time-consuming elements of using writing in the classroom is preparation by the instructor and for the students in sufficient detail such that neither will be surprised at grading.

Peer evaluation can also be incorporated. Once criteria are clear, students can become more familiar with those criteria and practice critical thinking skills by applying them to each other's work. In addition to helping students learn in multiple ways, peer critiques also provide students with feedback while also reducing instructor time spent dealing with writing. 
Nonetheless, scoring writing creates apprehension in many instructors, and with good reason. In addition to clear rubrics established in advance, other techniques allow for writing to be scored in a consistent and time-efficient manner. Working with teaching assistants to norm a few papers and then divide the labor is one technique, as is the relatively new process of calibrated peer review (Fosmire, 2010). Such strategies are important pieces of a larger puzzle that ultimately aims to help students learn how to write effectively.

Technical writing within courses allows students the opportunity to not only practice effective communication, but also provides a less stressful method of conveying ideas and questions. Well-implemented writing exercises can help build confidence as well as bring to the surface any gaps of understanding related to course content (Willis, 2011). Although the traditional methods of developing technical writing within an engineering course are well known, it is important to look how many different approaches might be used in many different existing courses in order to find the right strategies to create successful implementations that enhance student learning related to both writing and other key outcomes. To delve more deeply into this space of possibilities, it is worth briefly reviewing two main types of potential writing assignments:

(1) Incidental Writing Exercises: Incidental writing focuses on encouraging free-thinking in students and often coincides with other class activities as a way of helping students better understand material in a less formal setting (Hawkins, Coney, \& Bystrom, 1996). Types of incidental writing include, but are not limited to, activities such as journal writing, "think pieces", blog entries, and lab books/ notebooks. For journal, lab book, and notebook writing, students are assigned to write down thoughts about the course throughout the semester, thereby helping them to convey ideas and questions without having to worry about the pressure of doing so in front of a large class (Hawkins, Coney, \& Bystrom, 1996). Instructors can choose to either provide a writing prompt to help students choose a direction to write, or they can also assign free writing assignments with the only criteria being that students must produce something. Most examples of journaling appear to be successful utilizations with minimum additional work needed from instructors (Sharp, Olds, Miller, \& Dyrud, 1999). The term "think pieces" encompasses a few fast and easy writing activities that students complete to help organize their thoughts. An example of this would be to have students take the last five minutes of a lecture to summarize the topics covered in their own words, as well as to ask for clarification on any areas of confusion (Hawkins, Coney, \& Bystrom, 1996). Blog entries follow similar formatting to journaling except students post their completed writing on an online interface. The instructor can then choose whether to make these posts available to the other students for peer review and discussion or make all entries private (Willis, 2011).

All of these writing exercises are for the author's purpose only and are not focused on communicating information to a particular audience (Hawkins, Coney, \& Bystrom, 1996). A common issue with incidental writing assignments is striking a reasonable balance between encouraging free speech in the writing versus encouraging participation with feedback. Yet one of the major benefits of incidental writing activities lies with encouraging students to speak freely and not worry about getting an answer wrong. Substantial grading of such assignments can potentially counteract this main benefit. However, providing limited to no feedback on submitted 
writing assignments may discourage students from putting in full effort and subsequently not benefit from the assignments (Hawkins, Coney, \& Bystrom, 1996).

(2) Formal Writing Exercises: In contrast to incidental writing, formal writing involves more traditional assignments such as lab reports and semester class projects, and also includes instruction writing. Instruction writing is when students are charged with the task of creating a solutions manual for a given problem or instructional manual for a task (Sharp, Olds, Miller, \& Dyrud, 1999). An example would be having students write a solutions manual for an assigned weekly problem set. This type of writing proves valuable to both the students and instructors because it helps students communicate more efficiently and learn homework problems more thoroughly, and instructors can then use the solutions manual to help the class prepare for an exam. The main issue with formal writing is that these assignments create a substantial workload for instructors for grading and general feedback (Oakley, Connery, \& Allen, 1999).

The pairing of writing activities with courses is largely dependent on the class size and the number of instructors (instructor resources). As class sizes become smaller, longer writing assignments become more feasible and manageable, but consideration should always be given to the dwindling instructor resources in smaller classes as well. Technically any activity could be completed in any class without adding a substantial burden if grading and feedback were completely avoided, yet in order for these assignments to be most effective, care should be taken to match up activities with appropriate classes. Because of the limited amount of feedback necessary to make the assignments worthwhile, the majority of incidental writing activities can be used in all size classes without overburdening instructors with a larger work load. Also, instruction writing, such as the creation of solutions manuals, requires minimal additional feedback to be effective and can actually lower work load for instructors in the long run. These advantages can be amplified when students are involved in peer reviewing, which adds an additional layer of quality control.

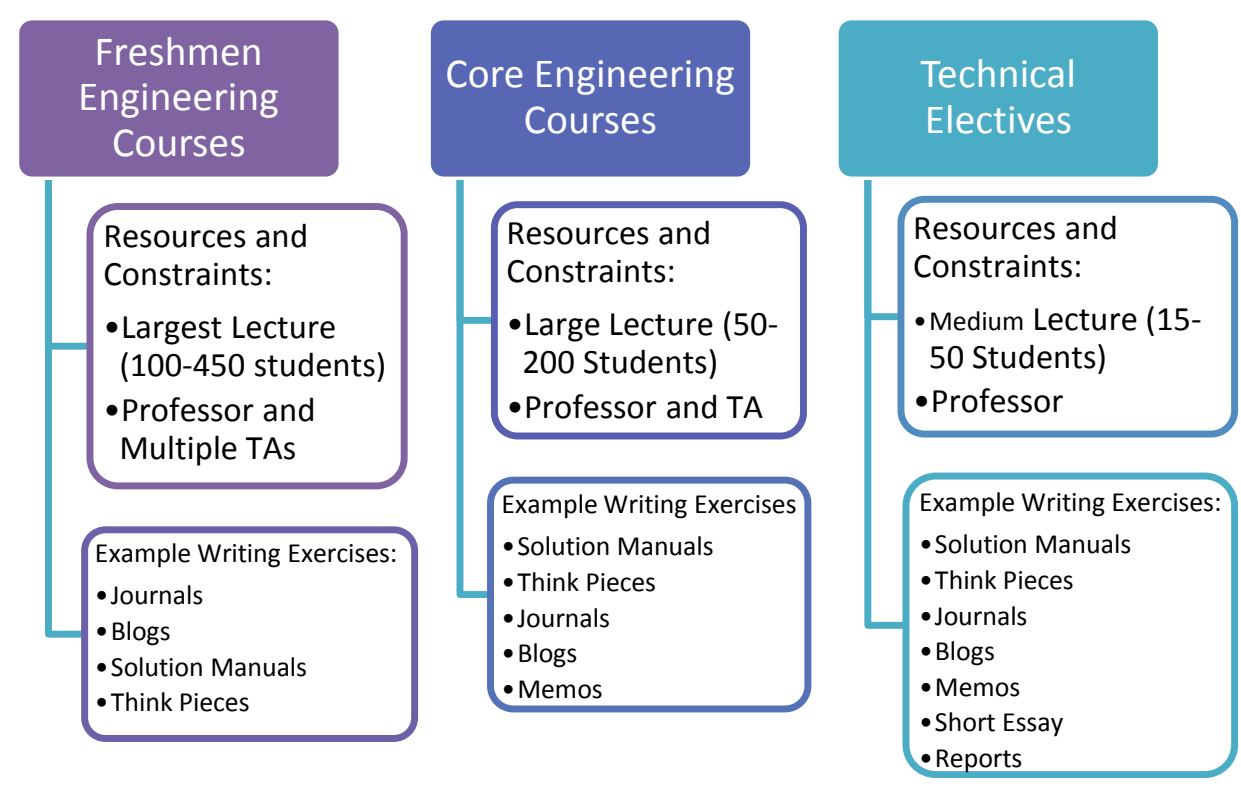

Figure 2: Pairing of Writing Exercises with Category of Course 


\section{Challenges to Incorporating Writing in Engineering}

In spite of the known benefits (and explicit requirements, e.g., from ABET) of including writing in the engineering curriculum, and the outspoken desire by employers and engineering organizations to improve the communication skills of graduates, technical communication remains a poorly addressed afterthought in even the country's top engineering programs. In a recent survey of the top 73 U.S. and Canadian engineering schools, Reave (2004) found that only about $50 \%$ of the top U.S. schools require a course in technical communication, and only $33 \%$ are pursuing some form of integrated instruction (Reave, 2004). This is not entirely surprising to those of us who have struggled to integrate communications into our engineering curricula and courses. Writing should be distributed across the engineering curricula, but substantial challenges often preclude the meaningful inclusion of writing in courses and curricula (ManuelDupont, 1996). Five of the most significant challenges inhibiting integration include:

Budgetary constraints: Teaching writing is resource-intensive (Craig, Lerner, \& Poe, 2008). With the current economic situation, technical communication resources are being placed on the chopping block, both directly and indirectly. When writing centers, communication specialists, teaching assistants, and graders are eliminated, departments no longer have the expertise or manpower required for dedicated communications courses or even the simple inclusion of writing exercises in courses. Even traditional writing elements of engineering programs such as laboratory reports are being eliminated in the current budget prices. This places the inclusion of technical communication elements - if they are to be included at all - squarely on the shoulders of the faculty teaching the technical courses.

Credit hour constraints: There is increasing pressure, for good reason, to encourage on-time completion of undergraduate engineering degrees. Credit hour requirements are systematically reducing, and if a program does not already have a dedicated writing course in place, it is very unlikely to add one. Moreover, existing technical communications courses are being eliminated to satisfy credit hour reductions. In some states, legislature-imposed credit hour caps have hastened this trend (Skirvin, 2012).

Lack of expertise: While most engineering faculty have strong technical writing skills as a necessary prerequisite for their publishing requirements in academia, these faculty most often have no experience in teaching technical writing, and moreover may not even have a strong understanding of what makes a good writer (Hawkins, Coney, \& Bystrom, 1996). While "good technical writing should speak for itself", when it does not, engineering faculty most often find themselves at a loss for how to correct it. Teaching assistants are generally even less skilled in technical writing instruction than their faculty supervisors, especially international teaching assistants for whom English may be a second language.

Time constraints: As is well-recognized, traditional technical writing assignments in engineering courses, such as report writing, often require heavy time commitments from instructors (Bonk, Imhoff, \& Cheng, 2002). Moreover, traditional exercises place a substantial additional workload on students, who may be struggling with the regular technical workload of their program. 
Low faculty motivation: The belief that writing is not important to engineering programs is held by many faculty and students (Ludlow \& Schulz, 1994). Additionally, even faculty who recognize the importance of writing may not have any institutional motivation to incorporate writing into their courses - or any pedagogical change, for that matter ( $\mathrm{Zhu}, 2004)$. This is especially true for research-intensive universities where there is little motivation for pedagogical experimentation, given the inefficiency of the process.

There is no easy panacea for all such challenges. In particular, budget and resource constraints will likely always be factors that threaten the inclusion of writing in engineering, due to its resource-intensive nature. However, we argue that the most resilient and sustainable solution for many of these challenges lies with a model in which writing is distributed across the engineering curriculum; we have also described how this strategy is the most pedagogically sound.

Unfortunately, the distributed model of including writing in engineering also amplifies the instructor-level challenges, e.g., lack of faculty expertise, time limitations, and low motivation to include writing in their courses (often for good reasons that are tied to resource, incentive, and time limitations). For these reasons, we believe that course- and instructor-level challenges are the most critical obstacles that impede the diffuse integration of writing within engineering curricula (Manuel-Dupont, 1996). As we briefly describe below, our own efforts are therefore focused on development and investigation of classroom techniques that address these challenges.

\section{Project Overview}

Our research team is tackling these types of challenges with support from a recently-awarded NSF Research Initiation Grant in Engineering Education (RIGEE, Award No. 1340491). Here we give an overview of this two-year project, including guiding research questions, hypotheses, objectives, and project goals.

\section{Research Questions}

Our project is organized around three primary research questions related to the classroom integration of writing in engineering:

1) What faculty-level barriers inhibit the inclusion of writing in engineering courses?

2) Which instructor-friendly, widely-transferrable writing exercises for engineering courses are most effective at increasing student learning of both technical content and communication skills?

3) Can we effectively transfer these techniques to faculty in a way that results in their longterm adoption and use?

\section{Hypotheses}

Our project plan is based on three main hypotheses that address these research questions, which will be tested in this project and in the longer-term effort that this project hopes to catalyze. First, we propose that faculty are more likely to implement writing in their courses if we can demonstrate (quantifiably) and communicate the tangible benefits of including writing in their 
courses. More specifically, we intend to show that writing increases learning of the technical material in their courses, and additional learning objectives are easily incorporated into courses where writing is involved (e.g. ABET non-technical skill outcomes, program-specific outcomes). Second, we hypothesize that extensive assessment and feedback is not required in order to create student learning gains in technical writing; moreover, the assessment workload can be greatly reduced with the adoption of a holistic grading rubric. In line with this claim, we suggest that significant gains in writing can be obtained in writing simply through practice, although these gains may only be perceivable over multiple semesters of practice. Further, rubrics, peer evaluation, and writing-to-learn exercises can all be used to reduce the time-intensiveness of grading writing.

Third and finally, we propose that effective and easy-to-adopt writing exercises for engineering courses need not be separate or additional writing assignments, but can rather dovetail with existing homework assignments. That is, typical homework problems can provide ample opportunity to practice writing, simply by altering the required solution presentation and format. Such exercises are also easily implemented in both large-lecture courses and smaller technical electives.

\section{Project Goals}

The project work plan is designed to focus on the above research questions and hypotheses, bringing together and leveraging the research team's expertise in civil engineering, engineering education, and communication. We are focusing on the immediate need for improved, readilytransferrable techniques for the incorporation of technical writing in engineering courses, most typically at the sophomore and junior levels. The premise with selecting the sophomore and junior levels is that most programs "bookend" technical writing in some fashion, with freshmanlevel design courses and senior-level capstone courses often being more project-based and already involving substantial writing. In contrast, the sophomore and junior levels tend not to include much writing beyond formatted laboratory reports, although with resource limitations even these reports have been eliminated from many programs. Further, core courses and technical electives at the sophomore and junior levels have tended to be more resistant to innovation and reform. Four specific project goals provide further focus for our efforts:

\section{Goal 1: Identification and clarification of faculty-level barriers that inhibit the inclusion of} writing in engineering courses

As indicated above, we have hypothesized numerous potential factors (perceptions, resource limitations, and attitudes) that keep faculty from incorporating writing in their engineering and STEM courses. Some of these barriers are real (e.g. lack of expertise), and some are perceived (e.g. the belief that "writing is not important to technical skill development"). The first step in our project is to identify these factors in order to best align our developed pedagogical techniques to address and overcome these barriers.

During the initial stage of our work, we will document the level of technical writing currently implemented in our engineering curriculum, working from documentation associated with a recent ABET accreditation. We will also survey faculty to investigate the amount of writing used in their courses, to determine the sources of their resistance to including technical writing 
content in their courses, and to identify potential strategies that may lead to successful, long-term implementation of technical writing in their courses. This stage of our project will also involve systematic study of appropriate pairings between technical writing teaching techniques and course levels and resource levels, with an eye toward refine our hypotheses for successful implementation at the course level.

For this pilot project, we will conduct engineering faculty assessments with simple online surveys that more comprehensively elucidate and quantify these factors. These anonymous surveys will be conducted across the College of Engineering at both our university and approximately a dozen of our peer institutions, including faculty in every discipline-specific engineering schools (e.g. Civil, Mechanical, Agricultural and Biological, etc.).

The faculty surveys will be analyzed in order to determine the barriers to implementation as a function of course type and school-specific resource levels, to allow us to best tailor the writing exercises for different scenarios. The surveys will also identify the constraints under which faculty can implement (any) writing exercises in their courses, which will help us to ensure that our developed methods are sustainable beyond the project period.

These surveys will allow us to best answer questions such as "What faculty-level barriers inhibit the inclusion of writing in engineering courses?," and "What are desirable/required attributes for writing exercises in engineering courses as a function of course-type, resource levels, and instructor attitudes?" The results will provide key information needed to plan, implement, and assess the writing exercises for the subsequent project objectives.

\section{Goal 2: Development of effective and transferrable techniques that employ writing in engineering and STEM courses}

Once we have identified, quantified, and categorized the faculty-level barriers to the inclusion of writing using the college-wide survey, we will devise writing exercises that address these barriers. This work will borrow from existing literature on both the pedagogy of technical communication and active learning, some of which was described above.

For this preliminary project, we focus on one of the two primary types of standard engineering courses that are most likely to include little or no writing (in the absence of a comprehensive writing-across-the-curriculum program): (1) large lecture format required "core" courses and (2) traditional technical electives. Our initial focus is large sophomore- and junior-level lecture format courses, while subsequent work will broaden and adapt our approach to technical electives. The types of courses that we have in mind cover topics such as statics, dynamics and mechanics, fluid mechanics, materials, surveying, linear circuit analysis, and thermodynamics. These courses are typically required for undergraduate engineers and taught in a traditional large lecture format. Unless mandated by the individual department or school, instructors are unlikely to implement writing in these types of courses because of the large numbers and perceived additional workload associated with assessment of student writing. The unintended consequence of these logistics is that students can go for most of their sophomore and junior years with very little writing in any of their courses, which is one of the main reasons we focus on such courses. 
While the faculty surveys associated with Goal 1 will inform the techniques that we develop, implement, and assess in this phase of the project, we put forth a preliminary hypothesis regarding an appropriate set of writing exercises that further illustrate our project plan.

Sample Writing Exercise for Large Course: Student-produced homework solutions: As a simple sample activity that we can envision testing in this project, we highlight the use of studentproduced homework solutions for a large course (e.g., (Hanson \& Williams, 2008). All engineering and STEM courses have homework of some kind, with the standard engineering problem set forming the bread and butter of a young engineer's coursework, especially at the sophomore and junior levels. In this exercise, students perform their homework exercises as usual (for example, the weekly assigned collection of five or so end-of-chapter quantitative problems). With these usual solutions (typically scrawled equations and answers on engineering paper), students are additionally required to write about their solutions in some way. The level and requirements for this additional writing can be as simple as "write a paragraph describing your solution procedure", or as complex as the development of a polished homework solution manual document, either individually for select problems or with teams of students compiling individual solutions into a study guide distributed prior to an exam (one can imagine numerous permutations on the basic idea, ranging from simple to complex, which lends to its portability).

We highlight this exercise not because of its novelty, which is debatable, but rather because it has many of the attributes that we hypothesize will be important to "shoehorn" writing into large engineering core courses, namely: (1) it does not significantly change the pre-existing structure of either the course or the assignments; (2) tangible, obvious benefits exist to the instructor and student in the creation of study guides that presumably enhance student learning of technical material as well as communication skills; (3) this technique is readily transferrable among a wide range of courses, since all courses have homework; (4) the activity is readily scalable across institutions, instructors, and semesters - it can be implemented in either a TA/grader-assessed, peer-assessed, or no-assessment basis, making it more transferrable across varying resource climates and sustainable through periods of changing resource levels, and it can be as simple or complex as an instructor wishes (or has time for). The bottom line is that this activity guarantees that students will write, and will write in courses where they typically do not normally write, which we argue will lead to gains in writing and technical skill abilities.

Sample Writing Exercise for Large Course: Thought question: Another sample exercise involves developing simple add-on questions that force students to think about the importance and context of their calculations, e.g., "If the fluid flowing in the pipe for problem 2 is oil, write one paragraph describing the environmental issues associated with a current engineering problem in the news that involves oil-filled pipes" (e.g. Keystone pipeline). Certainly one such question is not going to turn an engineer into a global citizen, but the inclusion of many such exercises across the curriculum over four years would almost certainly have a powerful cumulative effect on an undergraduate engineer's way of thinking about solutions. Can we generate and disseminate a list of such questions that faculty a wide range of disciplines can easily add to their pre-existing assignments? We propose that if we can tie writing assignments to specific nontechnical ABET objectives, departments and faculty will be more likely to include writing in their courses. Existing textbook companions provide further inspiration for creating such prompts (e.g., Riley, 2012). 
Goal 3: Assessment of the efficacy of these techniques, from student learning and instructor perspectives

A key objective of the project is to establish the learning gains that we hypothesize will occur for the students who perform the writing exercises, both in written communication as well as technical (course-specific) learning. Additionally, we would like to assess the writing exercises from the faculty perspective, because if they are not easy to implement, then they are likely not sustainable and will not be adopted by other faculty and institutions.

Instructor Assessment: The Instructor Experience Survey will help the research team understand the experiences of all faculty and graduate teaching assistants involved with piloting the proposed interventions. It will feature five components: 1) demographics, 2) prior teaching experience, including use of writing in courses, 3) evaluation of quality of the writing activities, 4) reflections on the instructional experience, and 5) impressions of the student experience.

Student Writing Assessment: To perform controlled tests on the efficacy of our exercises, we will divide the large classes into two groups, determined according to course section, one of which will receive the exercises and one that will not. The assessments will include pre- and post- tests of student writing abilities, such as writing a paragraph to explain a graph. However, the specific assessment will clearly target the element of writing that we believe the implemented writing exercises address (e.g. organization, paragraph composition, etc.).

Student Technical Skill Learning Assessment: The technical skill learning assessment will be based simply on course performance (Hanson and Williams, 2008), but we will track various components of the student grades (homework, exams) to determine whether any particular element of the course shows learning gains.

Student Experience Assessment: Finally, a Student Experience Survey will help the research team understand the experiences of students who participate in the pilot interventions. It will feature four components: 1) demographics, 2) prior writing coursework and experiences, 3) evaluation of the quality of the writing activities, and 4) attitudes toward informal writing, technical writing, etc. Importantly, we will track the demographics of the students to see whether writing and learning gains correlate strongly with any particular demographic.

Goal 4: Development of materials for the dissemination of these writing techniques across engineering and STEM disciplines

The ultimate goal of the project is the piloting of a successful transfer of validated engineering writing exercises to faculty and courses beyond the project. Our final goal is therefore the development of short online training modules that allow faculty to select appropriate writing exercises for their courses and quickly learn how to implement them. We envision the development of a set of best practices for each technique, with each technique having multiple potential implementation strategies depending on the instructor resources (ranging from simple to more complex) and objectives (e.g. technical skill development vs. writing skill development). 
We will produce these materials on a website that contains lists of writing exercises appropriate for different course types, short videos discussing their implementation, supporting materials such as grading rubrics and sample questions, and supporting information/FAQs that highlight tips and challenges with each technique. These materials and videos will be refined throughout the project, as we will continually be learning from our training experiences with the faculty implementing our techniques, and the hope is that by the end of the project we will have figured out how to effectively and succinctly deliver the necessary information. The website will be publically available website, and platforms such as CLEERhub.org will be used to enable crosspromotion. The training materials will be further vetted in workshops we plan to organize at future American Society for Engineering Education (ASEE), American Society of Civil Engineers (ASCE), and Frontiers in Education (FIE) conferences.

\section{Preliminary Results: a paragraph writing exercise}

As preliminary pilot work to this project, we implemented a paragraph writing exercise in a large civil engineering course in fall of 2013 (Essig et al., 2014). This course was a required elementary fluid mechanics course with approximately 120 students and a traditional lecture format structure; we chose this class for the writing intervention because it is a junior-level technical course in which no structured writing typically occurs. For the pilot exercise, students were required to write one short paragraph per week in additional to their regular calculationbased homework problems; virtually no writing instruction was added to the class. Students were given a 5 point holistic grading rubric for the paragraphs, and an engineering graduate student assessed the weekly paragraphs and provided minimal markings in addition to the raw score. Students also completed two brief surveys about both writing in engineering and the paragraph writing exercise specifically.

The pilot exercise was successful in incorporating writing into a junior-level technical course, suggesting that the exercise could aid in extending writing further across the engineering curriculum to include courses often devoid of written communication. During the semester, students wrote responses to a variety of prompts including "explain a concept" questions, opinion pieces about large engineering projects, and "give an example" questions, which asked students to provide real-world examples of concepts and seemed effective in motivating students to find relevance in material being taught in class. Current work seeks to develop a set of transferrable guidelines for how to craft writing prompts in order to achieve different outcomes.

Many students struggled with the lack of feedback provided on graded paragraphs, and found the minimal marking and holistic rubric grading/assessment scheme challenging to understand. The scheme had been motivated by the (usual) desire to minimize the grading time required for the paragraphs, which was still substantial -2 or 3 minutes per paragraph - even with the minimal marking scheme. Possible low-overhead assessment improvements are being examined, including peer grading, no grading, and the development of a more complex minimal marking scheme. However, the pilot exercise highlighted the importance of providing writing-specific feedback and the allowance for revision in the writing process, and we are working to determine how to incorporate these elements under the constraints that originally motivated the project. 


\section{Conclusions}

The inclusion of writing in engineering courses is important, serving both to enhance student learning of technical and related material, as well as aiding in the development of written communication skills. However, the inclusion of writing in technical courses is challenging due to the resource-intensive nature of writing instruction, which - in its traditional form - requires substantial time and expertise in order to provide students with feedback to improve their writing. Our project seeks to develop transferrable best practices and techniques for including writing in engineering courses in a low-overhead manner that, because they do not place substantial additional burdens on the instructor, may be more easily adopted across a curriculum, providing students with the continual, meaningful writing experiences that can greatly enrich their learning and their development of robust written communication skills. Early work on a paragraph writing exercise suggests that it is possible to include writing in traditionally technical (only) courses, provided that a sound assessment and feedback strategy can be implemented.

\section{Acknowledgments}

The authors acknowledge support for aspects of this work under National Science Foundation (NSF) Award No. 1340491, Research Initiation Grant: Writing to Learn Engineering: Identifying Effective Techniques for the Integration of Written Communication Into Engineering Classes and Curricula. 


\section{References}

ABET. (2012, October 27). Criteria for Accrediting Engineering Programs, 2013-2014. Retrieved March 11, 2013, from ABET Website: http://abet.org/DisplayTemplates/DocsHandbook.aspx?id=3149

Bazerman, C., Little, J., Bethel, L., Chavkin, T., Fouquette, D., \& Garufis, J. (2005). Reference guide to writing across the curriculum. West Lafayette: Parlor Press.

Bean, J. (1996). Engaging ideas: The professor's guide to integrating writing, critical thinking, and active learning in the classroom. San Francisco: Jossey-Bass.

Bonk, R. J., Imhoff, P. T., \& Cheng, A. (2002). Integrating Written Communication within Engineering Curricula. Journal of Professional Issues in Engineering Education and Practive, 152-159.

Buzzi, O., Grimes, S., \& Rolls, A. (2012). Writing for the discipline in the discipline? Teaching in Higher Education , 479-484.

Craig, J. L., Lerner, N., \& Poe, M. (2008). Innovation Across the Curriculum: Three Case Studies in Teaching Science and Engineering Communication. IEEE Transactions on Professional Communication, 280-301.

Dym, C. L., Agogino, A. M., Eris, O., Frey, D. D., \& Leifer, L. J. (2005). Engineering Design Thinking, Teaching, and Learning. Journal of Engineering Education, 103-120.

Essig, R., Troy, C., Jesiek, B., \& Boyd, J. (2014). Adventures in paragraph writing: the development and refinement of scalable and effective writing exercises for large enrollment engineering courses. ASEE Conference Proceedings.

Felder, R. (1988). Learning and Teaching Styles in Engineering Education. Engineering Education, 78(7), 674-681.

Felder, R., Woods, D., Stice, J., \& Rugarcia, A. (2000). The Future of Engineering Education II. Teaching Methods That Work. Chemical Engineering Education, 1, 26-39.

Ford, J., \& Riley, L. A. (2003). Integrating Communication and Engineering Education: A Look at Curricula, Courses, and Support Systems. Journal of Engineering Education, 325-328.

Fosmire, M. (2010). Calibrated peer review: A new tool for integrating information literacy skills in writing-intensive large classroom settings. portal: Libraries and the Academy, 10(2), 147-163.

Hanson, J., \& Williams, J. M. (2008). Using Writing Assignments to Improve Self-Assessment and Communication Skills in an Engineering Statics Course. Journal of Engineering Education, 515-529.

Hawkins, S., Coney, M. B., \& Bystrom, K.-E. (1996). Incidental Writing in the Engineering Classroom. Journal of Engineering Education, 27-57.

Held, J. A., Olds, B., Miller, R., Demel, J. T., Audeen, F., Cain, K., et al. (1994). Incorporating Writing in Engineering Classes and Engineering in Writing Classes. IEEE, 628-632.

International Federation of Engineering Education Societies. (2013). The attributes of a global engineer project. Milwaukee, WI. Retrieved from http://www.sefi.be/ifees/wpcontent/uploads/WEEF-2012-Attributes-of-a-Global-Engineer.pdf

Jenkins, S., Jordan, M. K., \& Weiland, P. O. (1993). The Tole of Writing in Graduate Engineering Education: A Survey of Faculty Beliefs and Practices. English for Specific Purposes, 12, 51-67. 
Levine, K. J., Allard, S., \& Tenopir, C. (2011). The Changing Communication Patterns of Engineers. IEEE, 1155-1157.

Light, R. (2004). Making the most of college: Students speak their minds. Cambridge: Harvard University Press.

Ludlow, D. K., \& Schulz, K. H. (1994). Writing Across the Chemical Engineering Curriculum at the University of North Dakota. Journal of Engineering Education, 161-168.

Manuel-Dupont. (1996). Writing-Across-the-Curriculum in an Engineering Program. Journal of Engineering Education, 35-40.

National Academy of Engineering. (2004). The Engineer of 2020: Visions of Engineering in the New Century. Washington DC: The National Academies Press.

Oakley, B., Connery, B., \& Allen, K. (1999). Incorporating Writing Skills into the Engineering Curriculum. IEEE, 18-21.

Olds, B. M., Dyrud, M. A., Held, J. A., \& Sharp, J. E. (1993). Writing in Engineering and Technology Courses. Proceedings of the Frontiers in Education Conference, (pp. 618$622)$.

Petraglia, J. (1995). Reconceiving Writing, Rethinking Writing Instruction. Mahwah: Lawrence Erlbaum Associates, Inc.

Plumb, C., \& Scott, C. (2002). Outcomes Assessment of Engineering Writing at the University of Washington. Journal of Engineering Education, 333-338.

Reave, L. (2004). Technical Communication Instruction in Engineering Schools: A Survey of Top-Ranked US and Canadian Programs. Journal of Business and Technical Communication, 452-490.

Riemer, M. J. (2007). Communication Skills for the 21st Century Engineer. Global Journal of Engineering Education, 89-100.

Russell, D. (1992). American origins of the writing-across-the-curriculum movement. In C. Bazerman, \& D. Russell, Landmark essays on writing across the curriculum (pp. 3-22). Davis: Hermagoras Press.

Sharp, J. E., Olds, B. M., Miller, R. L., \& Dyrud, M. A. (1999). Four Effective Writing Strategies for Engineering Classes. Journal of Engineering Education, 53-57.

Skirvin. (2012, February 21). Three Reasons Universities Aren't Worried About 'Credit Creep'. Retrieved March 27, 2013, from State Impact: Indiana Education, From the Capitol to the Classroom: http://stateimpact.npr.org/indiana/2012/02/21/three-reasons-universitiesarent-worried-about-credit-creep/

Walker, K. (2000). Integrating Writing Instruction into Engineering Courses: A Writing Center Model. Journal of Engineering Education, 369-375.

Wheeler, E., \& McDonald, R. L. (2000). Writing in engineering courses. Journal of Engineering Education, 481-486.

Whiteman Farr, M. (1981). Dialect influence in writing. In M. Whiteman Farr, Variation in Writing Functional and Linguistic-Cultural Difference. Hillsdale: Erlbaum.

Willis, J. (2011). Writing Sprouts Conceptual Brain Networks from the STEM of Math and Science. STEM Magazine, 11-18.

Winsor, D. A. (1990). Engineering Writing/Writing Engineering. College Composition and Communication, 58-70.

Zhu, W. (2004). Faculty views on the importance of writing, the nature of acedemic writing, and teaching and responding to writing in the disciplines. Journal of Second Laungage Writing, 29-48. 


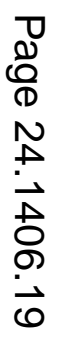

